\title{
SCANNING ELECTRON MICROSCOPE OBSERVATIONS ON THE MIRACIDIUM OF SCHISTOSOMA
}

\author{
P. T. LOVERDE \\ Mollusc Division, Museum of Zoology, The University of Michigan, Ann Arbor, Michigan 48104, U.S.A.
}

(Received 9 May 1974)

\begin{abstract}
LoVerde P. T. 1975. Scanning electron microscope observaticns on the miracidium of Schistosoma. International Journal for Parasitology 5: 95-97. Miracidia of two specics of Schistosoma, viz. haematobium and japonicum, were studied with the scanning electron microscope to more clearly visualize what is seen with the light microscope and the transmission electron microscope, and more specifically, to relate the structure of the apical papilla to its function in snail penetration.

The apical papilla of schistosome miracidia is composed of corrugated areas which form tiny suckerlike cups, presumably used by the miracidium to facilitate attachment to the snail during penetration. A lateral opening (secretory pore) on the apical papilla and short stubby apical cilia (tactile or sensory) are also demonstrated.
\end{abstract}

INDEX KEY WORDS: Srhistosoma; miracidium; apical papilla; SEM; penetration; snail.

\section{INTRODUCTION}

The PENETRATION of the trematode miracidium into the snail intermediate host is an important part of a trematode life-cycle. The penetration process includes attachment of the miracidium to the snail host surface and subsequent entry through the snail dermis. The miracidium's apical papilla is thought to be of prime importance in accomplishing penetration, and some studies have been directed toward elucidating this problem. In this regard species of Fasciola and Schistosoma have received the most attention. Observations have been made with the light microscope (Dawes, 1960; Wajdi, 1966) and the transmission electron microscope (Wilson, 1969; Wilson, Pallin \& Denison, 1971; Kinoti, 1971). They have been recently reviewed by Booker (1972), Hockley (1973) and Wright (1971).

Ultrastructural studies on miracidia of Schistosoma mattheei and $S$. mansoni have shown the apical papilla to consist of an anastomosing network of apical filaments or processes (see Kinoti, 1971, pls. I, II, III : Wright, 1971, pl. VI) which presumably are the walls of tiny sucker-like cups (Booker, 1972; Wright, 1971) that form a mini sucker pad (Kinoti, 1971) which assists in attachment of the miracidium to the snail in early stages of penetration.

The purpose of the current study was to use the Scanning Electron Microscope (SEM) to more clearly visualize what is seen at the light microscope and electron microscope levels and to relate structure of the apical papilla to its function in snail penetration. My results complement the previous studies of Booker (1972), Kinoti (1971), Wajdi (1966) and Wright (1971).

\section{MATERIALS AND METHODS}

The SEM was employed to investigate the apical papilla of $S$. japonicum and $S$. haematobium miracidia. Materials used in this study were provided by the U.S.Japan Cooperative Medical Science Program, NIAID. The miracidia were fixed in Párducz solution (Párducz, 1967), rinsed twice in distilled water, quick-frozen in a dry ice-acetone mixture, lypholized, gold-coated in a vacuum evaporator by ionizing radiation and observed in a JEOL (Ltd.) JSM-U3 SEM.

\section{OBSERVATIONS AND DISCUSSION}

The photographs show a mini sucker pad composed of tiny sucker-like cups (Figs. 1-5), as postulated by Booker (1972), Kinoti (1971) and Wright (1971).

The SEM photographs suggest that the "tangle of microville" observed at the ultrastructural level by Kinoti (1971) and Booker (1972) are corrugated areas which form tiny sucker-like cups used by the miracidium to facilitate attachment to the snail. Similar areas have been described for the miracidium of Fasciola (Wilson, 1969). It is also possible that the tip of the apical papilla can be invaginated to form a sucker-like cup as described for $F$. hepatica (Wilson et al., 1971).

It is thought that both snail host location and the ability to penetrate the snail dermis involves physical and chemical activities by the miracidium. So far in those miracidia that have been examined by other authors it has been shown that the greatest concentration of receptors is on or around the apical papilla (Booker, 1972). Ultrastructural studies also have demonstrated an apical gland, secretory canals 


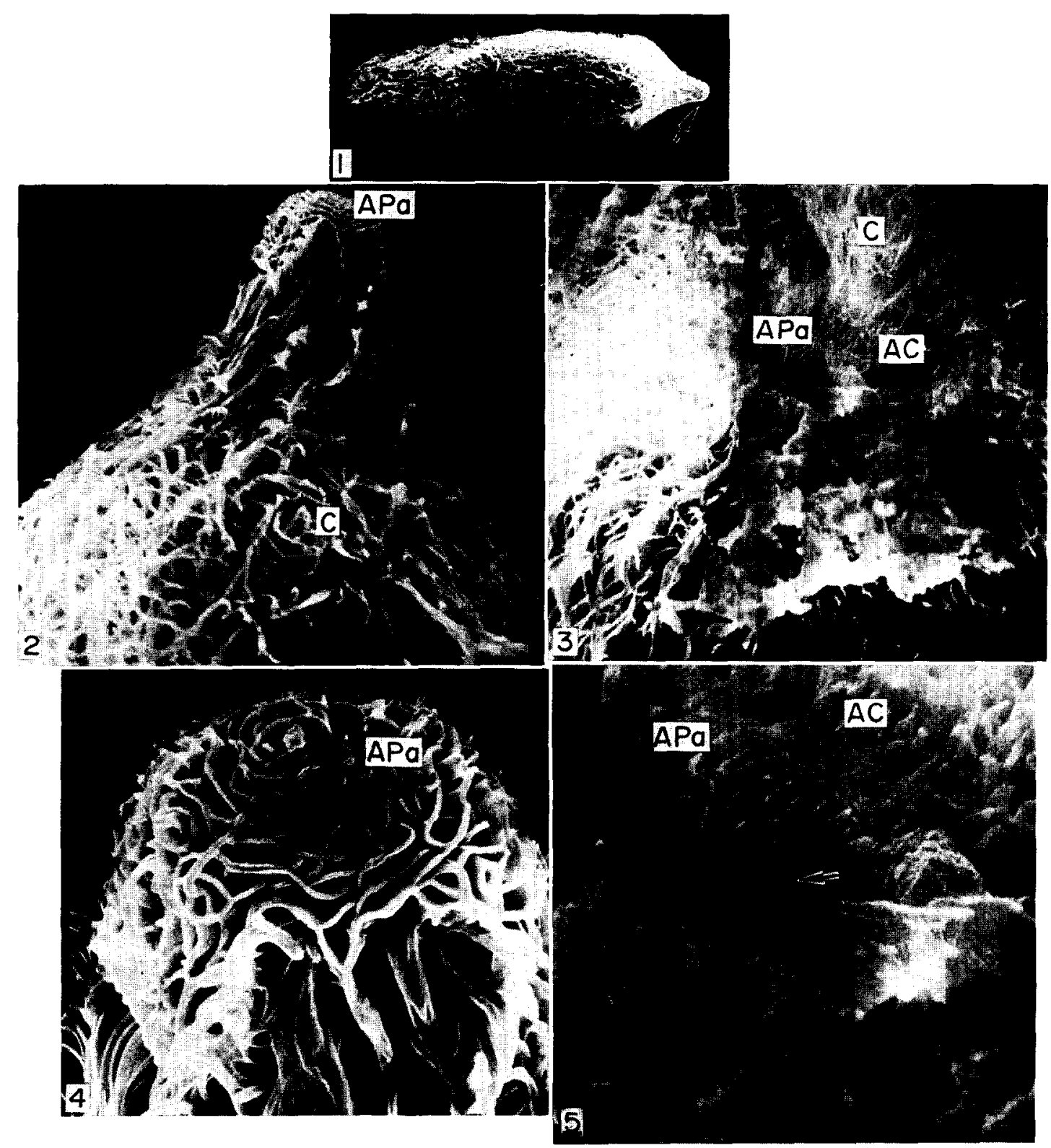

FIG. 1. Miracidium of Schistosoma haematobium. Arrow denotes location of apical papilla. 500.

FIG. 2. Apical papilla (A pa) of Schistosoma haematobium miracidium surrounded by locom otor cilia (C). $\times 3000$.

FIG. 3. Apical papilla (A Pa) of Schistosoma japonicum miracidium. 3000.

FIG. 4. Apical papilla (A Pa) of Schistosoma haematobium miracidium showing a mini-sucker pad composed of tiny sucker-like cups. 10,000 .

FIG. 5. Apical papilla (A Pa) of Schistosoma japonicum miracidium showing a mini-sucker pad composed of tiny sucker-like cups, with a secretory pore (arrow) surrounded by tactile apical cilia (AC). $\% 10,000$.

and the presence of external substances supposedly secreted by the miracidium (see Hockley, 1973). In the current study an external opening (secretory pore) communicating to the lateral side of the apical papilla has been demonstrated (Fig. 5, arrow) as well as short stubby apical cilia, which presumably have a tactile function (Figs. 3,5). The area of the apical papilla appears to differ between the two species of Schistosoma (Figs. 4,5 ). However, whether this is a true genetic difference, or due to an artifact of preparation or due to different physiological states of the miracidia at the time of fixation, is not 
known. The latter seems plausible to explain the pronounced nature of the excretory pore, i.e. the miracidium was most likely in the act of secretion.

Acknowledgements-I would like to thank Dr. J. B. Burch, University of Michigan, for his efforts in improving the manuscript, Dr. W. Bigelow for the use of the scanning electron microscope facilities at the University of Michigan, and Dr. E. G. Berry, University of Michigan, for providing the schistosome materials. This work was supported, in part, by a research grant from the National Institute of Allergy and Infectious Diseases, U.S. Public Health Service (N.I.H. Training Grant No. 5 T1 Al 60).

\section{REFERENCES}

Booker B. E. 1972. Sense organs in trentatode miracidia. In Behavioral Aspects of Parasite Transmission, (Edited by CanNing E. U. \& Wright C. A.), pp. 171-180. Academic Press, London.

DAwEs B. 1960. A study of the miracidium of Fasciola hepatica and an account of the mode of penetration of the sporocyst into Lyminaea truncatula. In Libro Homenaje al Dr Eduardo Caballero y Caballero, pp. 95-111. Nacional de Ciencias Biológicas, Mexico.

Hockley D. J. 1973. Ultrastructure of the tegument of Schistosoma. Advances in Parasitology $11: 233305$.

Kinot G, K. 1971. The attachment and penetration apparatus of the miracidium of Schistosoma. Joumal of Helminthology 65:229-235.

PÁRDUCZ B. 1967. Ciliary movement and coordination in ciliates. International Review of Cytology 21, 91-198.

WAJDI N. 1966. Penetration by miracidia of Schistosoma mansoni into the snail host. Journal of Helminthology 40: $235-244$.

WILSON R. A. 1969. Fine structure of the tegument of the miracidium of Fasciola hepatica. Soumal of Parasitology 55: 124-133.

Wilson R. A., Pullin R. \& Denison J. 1971. An investigation of the mechanism of infection by digenetic trematodes: the penetration of the miracidium of Fasciola hepatica into its snail host Lymnaea truncatula. Parasitology 63: 491-506.

Wright C. A. 1971. Flukes and Shails, George Allen \& Unwin, London. 